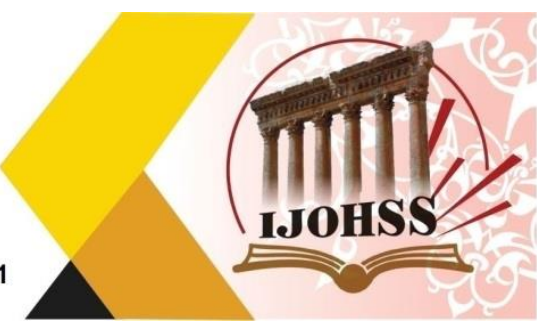

\title{
Graphic Tools: Utilization of Glasses and Ceramics in Fine Arts
}

\author{
Shayma Haleem Naji \\ College of Engineering \\ Al- Muthanna University \\ Iraq \\ Email: neasma11@yahoo.com
}

\begin{abstract}
Fine art is known as "a visual art that is contemplate to have been originate in essence for artistic and creative purposes and evaluate for its beauty and full of meanings. This word "fine" does not express the aspect of the artistry in question, but the cleanliness of practice confers to traditional Western European canons. Graphic art spread expansive range of visual aesthetic interpretation, mainly 2-D, for example produced on a flat surface. Exempt in the view of architecture, where efficient efficacy was accepted, this defines basically eliminate the "effective" applied or embellishing arts, and the products were observed as crafts. In existent practice, these divergence and restraint have become originally meaningless, as the conception or objective of the artist is given authority, disregarding of the means through which this is expressed.
\end{abstract}

Keywords: Graphic, Aesthetic, contemplate, artistic, traditional, western European, effective, embellishing, authority, expansive. 


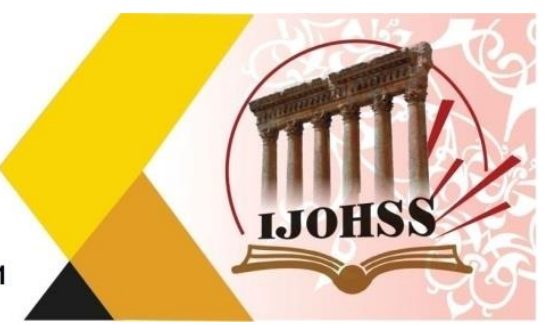

\section{INTRODUCTION}

Art is immensely divergent field of human action hooked in initiate optic, acoustic, or execute commodity artistry that indicate the author's extravagant or high tech art, and are planned to be appreciative. The oldest chronicle forms of art are optic arts, which comprises images or objects in retrieve like painting, sculpture, printmaking, photography, and other optic media. Graphic arts is mainly depends on line or tone of the paintings than colors... lining and tone only decides the how the paintings will be. Architecture is generally constituted as one of the visual arts. However, like the embellishing arts, it constitutes the formulation of objects where the efficient deliberations of use are fundamental, commonly are not in another optic art, like a painting. Art may be represented in terms of pastiche (its representation of reality). Though the interpretation of what composes art is contradict and has altered from time to time, general depiction center on the idea of extravagant or high tech art emanate from creation. When it comes to visually analyze a work of art, there is no single set of values or artistic peculiarity.

Fine art is one of the arts known. Fine art is known as "a visual art that is contemplate to have been originate in essence for artistic and creative purposes and evaluate for its beauty and full of meanings. This word "fine" does not express the aspect of the artistry in question, but the cleanliness of practice confers to traditional Western European canons. Exempt in the view of architecture, where efficient efficacy was accepted, this defines basically eliminate the "effective" applied or embellishing arts, and the products were observed as crafts. Ceramics and glasses used widely in fine arts nowadays. Since archaic times, ceramics and glass has been combined with incredible artistry. Generally 30,000 years ago, clay-based statues were constructing to produce and show animals and spiritual symbol, whereas after some time dated porcelain was formed not only to hold liquids (e.g., water, wine, and oil) and food, but also to interpret stories and provide pictures of ancient life. Pottery is the most economical and reasonable and boundless type of ceramic art. It endure to be related with local cultures depicting shapes, sizes, and patterns of implication for those people living in to the people living in a assured areas, and most often clearly diagnose the area and region of provenance . For example, Native American vases are always symbolized comparably simple diagram in geometrics, in those not used more than four colors. Not only this ...generally are the flowers, animals also painted. 


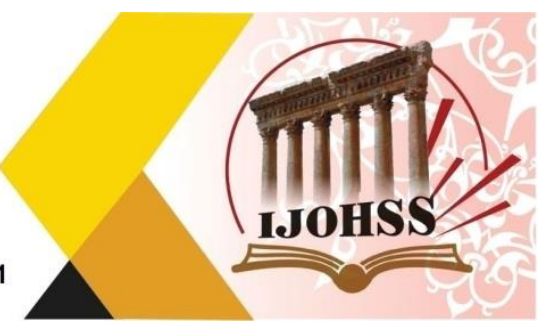

\section{LITERATURE REVIEW}

In History, hi- Tech discovery or inventions have made the evolution of graphic art. In $2500 \mathrm{BC}$, the Egyptians were use graphic arts to symbolize to disseminate their reflection of their thinking's in a written form known as hieroglyphics. The Egyptians wrote and illustrated narratives on rolls of papyrus to share the stories and art with others .Ceramics is the utmost archaic industries before thousands of years ago. When humans invented clay formed in affluence and made into objects. This process is done by mixing with water and then firing, this lead to the invention of an industry, the ceramic which was used before ceramic commodity is dated as early as 28,000 BCE, during the Stone Age. It is a statue of a woman, named the Venus. Here along with this, hundreds formed of clay exhibiting animals was also disclosed near the leftover. The first examples of porcelain arose in Eastern Asia several thousand years later. In the cave in China, remnant of pots dated to 18,000-17,000 BCE has been initiated. Cleanliness of practice confers to traditional Western European canons. Exempt in the view of architecture, where efficient efficacy was accepted, this defines basically eliminate the "effective" applied or embellishing arts, and the products were observed as crafts. Ceramics and glasses used widely in fine arts nowadays Uses of ceramics elevated adequately during the Neolithic period, with the formation of established communities devoted to farming. Starting generally in 9,000 BCE, the ceramics which is clay based became famous as containers for water and food, art objects, tiles and bricks, and their transmission from Asia to the Middle East and Europe. Adequate use of ceramics during the Stone Age, with the formulation of established association devoted to agriculture and farming. Starting generally in 9,000 BCE the outcome made of clay was used as a container for day to day life for storing food water etc... In starting the products were dried in fire with high temperature or in the sun ....temperature (below $1,000^{\circ} \mathrm{C}$ glittered porcelain was introduced in Mesopotamia. Factories started creating glass based porcelain in Egypt Improvement in the artifact of ceramics was the discovery of the wheel, in 3,500 BCE. After World War II, ceramics and glass have subsidized in the growth of many automation advanced fields, including electronics, optoelectronics. Modernization in ceramic transformation and classification capability has empowered the formulation of materials with properties that fulfill the demand of personalized applications. In these years, ceramic alteration attained new vigor from nanotechnology, which allowed producer to produce the outcome with lots of properties kike transparency, ductility, elasticity etc..... 


\section{المجلة الدولية اللعلوم الإنسانية والإمتصاعية}

International Journal on Humanities and Social Sciences website:www.ijohss.com Email:editor@ijohss.com ISSN: 2415 - 4822

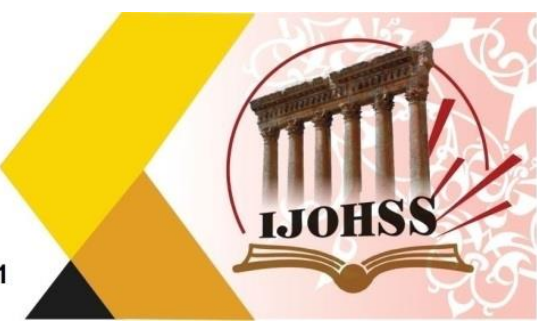

Some of the summary breakthrough history of ceramics and glass is provided in the table below

\begin{tabular}{|l|l|}
\hline BCE & Evolution \\
\hline 28,000 & Ceramic moppet is used for liturgical purposes. \\
\hline 18,000 & Chinese porcelain. \\
\hline $\begin{array}{l}18,000 \text { to } \\
14,000\end{array}$ & Ceramic porcelain advancement in Eastern Asia. \\
\hline 9,000 & Ceramic products were popular for example: tiles stone bricks etc.... \\
\hline 7,000 & Natural glass made sharp tools. \\
\hline 5,000 & Phoenic merchants possibly make the first glass. \\
\hline 3,500 & Simple glass items are fabricated in Mesopotamia and Egypt. \\
\hline
\end{tabular}
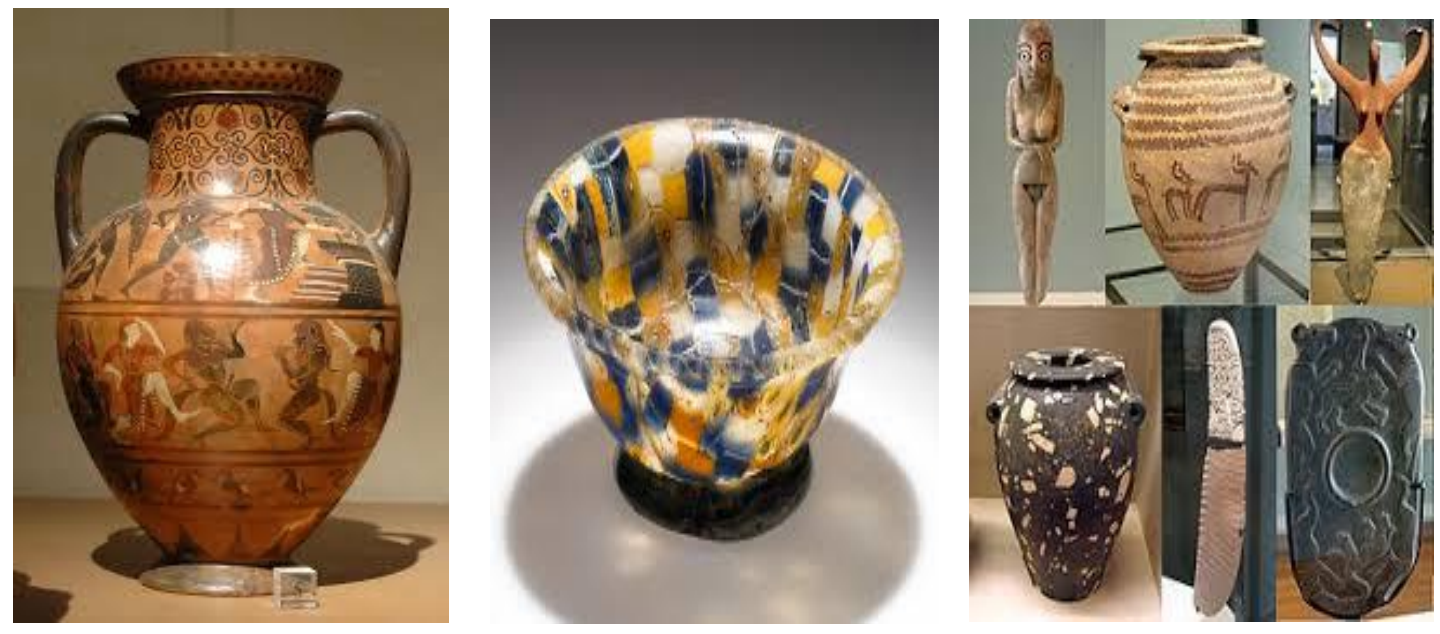

Fig:1 Ceramics based

Fig 3 : Art of Ancient Egypt 


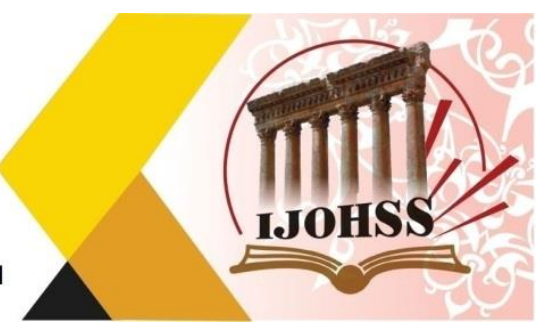

\section{METHODOLOGIES}

Since archaic times, ceramics and glass has been combined with incredible artistry. Generally 30,000 years ago, clay-based statues were construct to produce and shows animals and spiritual symbol, whereas after some time dated porcelain was formed not only to hold liquids (e.g., water, wine, and oil) and food . Pottery is the most economical and reasonable and boundless type of ceramic art. It endure to be related with local cultures depicting shapes, sizes, and patterns of implication for those people living in to the people living in a assured areas, and most often clearly diagnose the area and region of provenance. For example, Native American vases are always symbolized comparably simple diagram in geometrics, in those not used more than four colors. Not only this ...generally are the flowers, animals also painted.

Pottery is the most economical and reasonable and boundless type of ceramic art. It endure to be related with local cultures depicting shapes, sizes, and patterns of implication for those people living in to the people living in a assured areas, and most often clearly diagnose the area and region of provenance. Italian porcelain is known for its vigorous colors and usually painted images which means something and reveals what it is used for. Porcelain appears in various sizes and of different shapes. Just for example coffee mugs, coffee cups, tray holder, salt and pepper porcelain etc... is just used for decoration purposes. Chinese pottery is extreme white embellished with blue images of intervolve flowers, leaves. Pottery made by Chinese is usually used as flower vase that is of different shapes and sizes and is used for decoration purposes Experts known that how to create the objects with the use of ceramics and glasses .. The best example is Chinese pottery, Italian porcelain like flower vases pots, coffee mugs, sculpture etc...there are , many ways by which artist creating the porcelain like concrete mixed with ceramics, clay mixed with ceramics, ceramics mixed with glasses etc... after mixture of this ceramics and concrete or clay or ceramics or ceramics and glasses the outcomes which we get is amazing and it is very easy too to form into various shapes and sizes. And later painted with different- different style. After this 3D printing has come in which experts getting better result in short period of time. Alison Britton, Roxanne Swentzell, Steven Young Lee, Kyungmin Park, are just some of the recent artists that known for their work. the another example of fine arts used by ceramics is tiles which is used almost in every home nowadays Tiles comes in different shapes and sizes and of different colors. And it can be 2-D and 3-D and it became popular... Glass also plays crucial role in fine art.it comes in 3-D shapes, stained glass, glass mosaics, paintings on glass, and hanging glass. Rather 

International Journal on Humanities and Social Sciences website:www.ijohss.com Email:editor@ijohss.com العدد (24) سبتمبر 2021 ISSN: 2415 - 4822

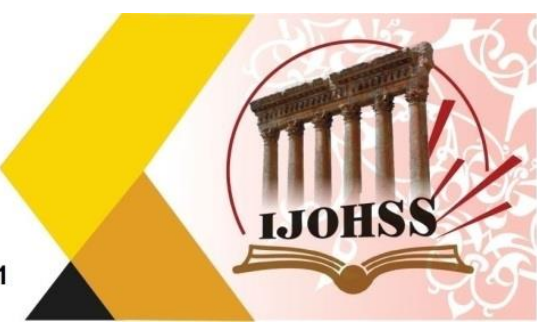

than this ceramics and glass used in fine arts comprised items used in jewelry and beads.

Ceramics and glass Art are shown as below:

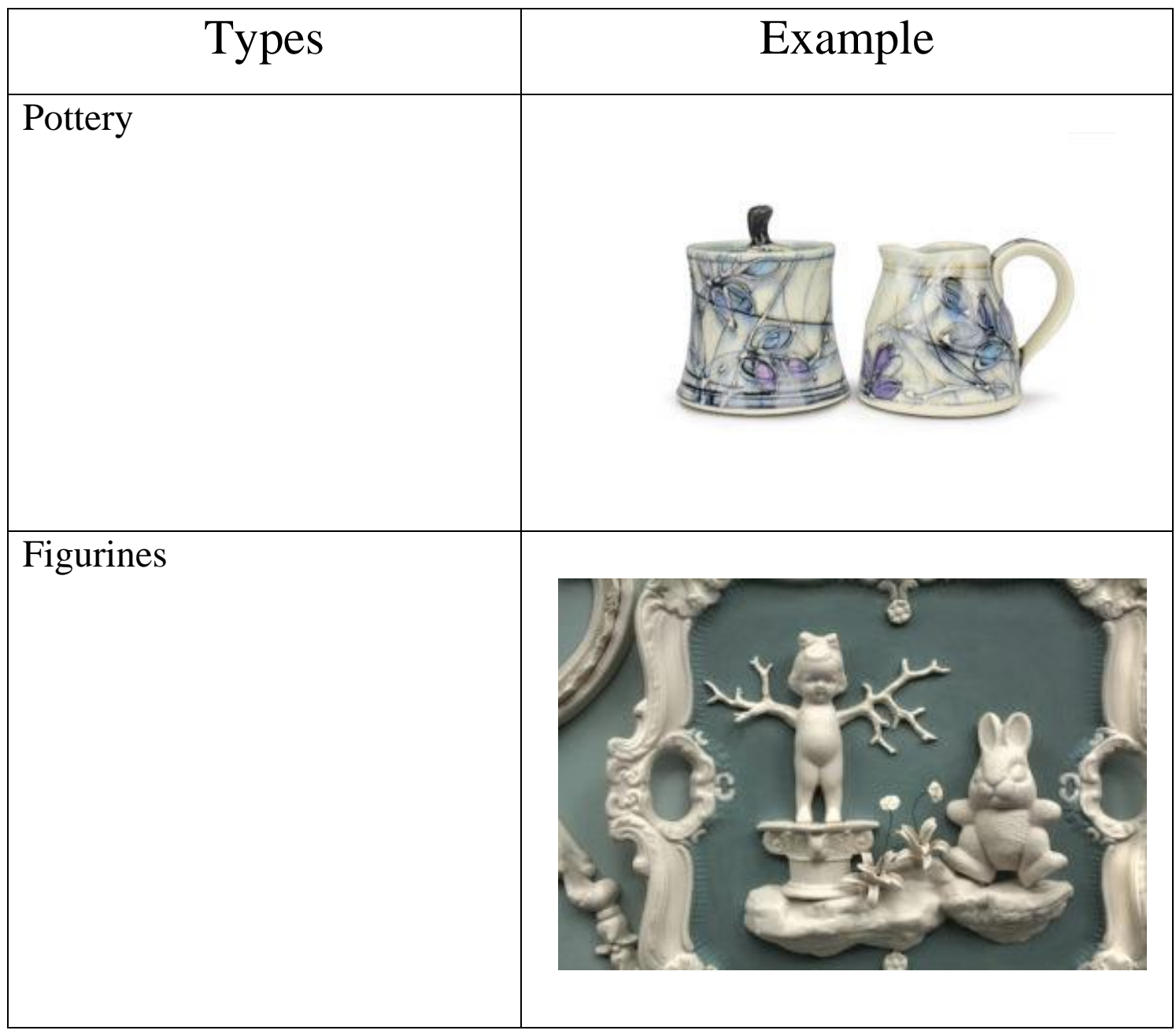


المجلة الحولية اللملوم الإنسانية والإمتماعية International Journal on Humanities and Social Sciences website:www.ijohss.com Email:editor@ijohss.com ISSN: 2415 - 4822

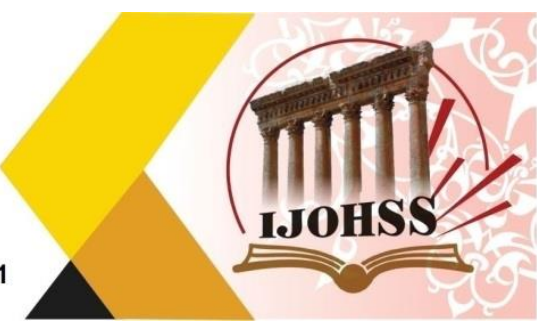

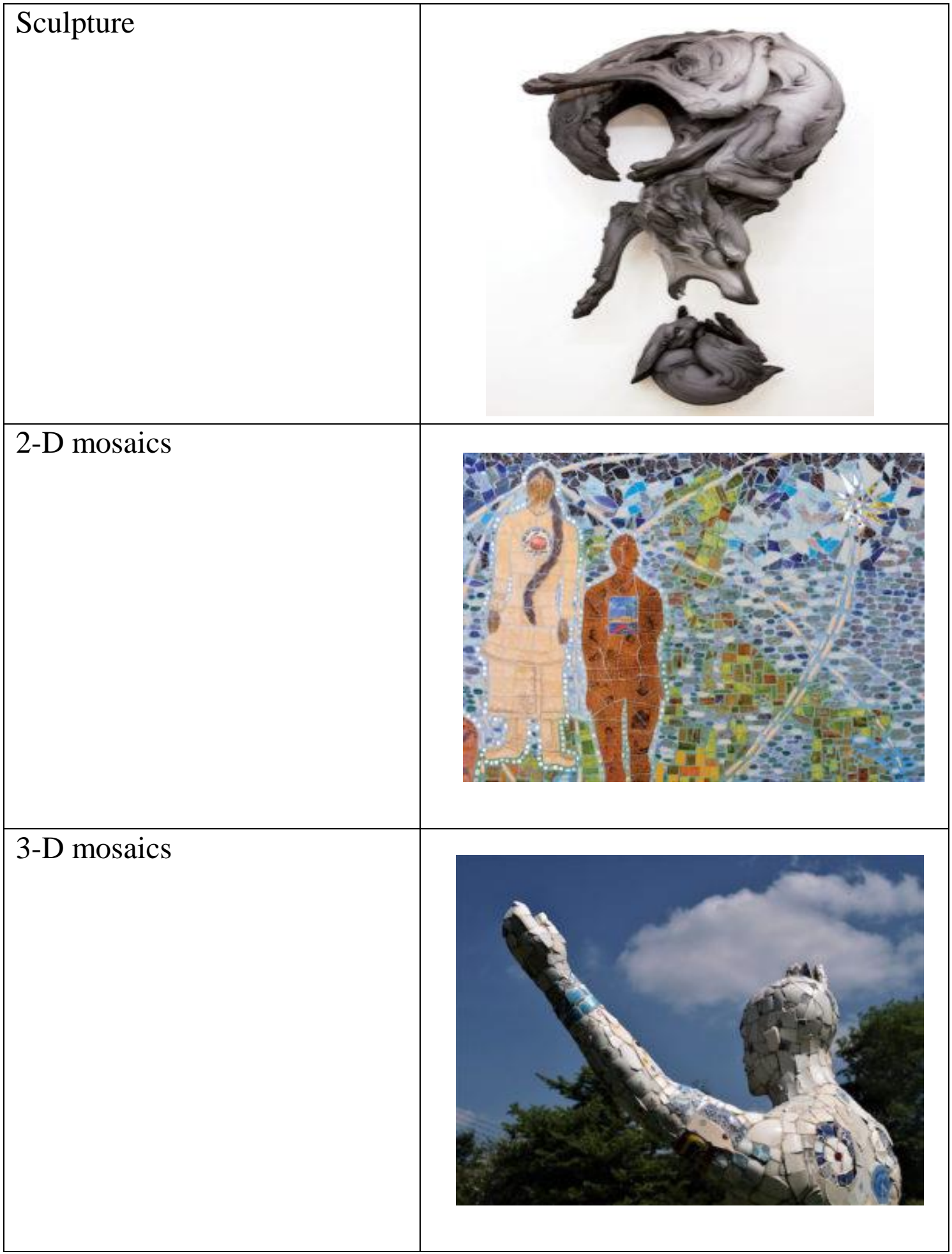


المجلة الحولية اللملوم الإنسانية والإمتماعية International Journal on Humanities and Social Sciences website:www.ijohss.com Email:editor@ijohss.com ISSN: $2415-4822$
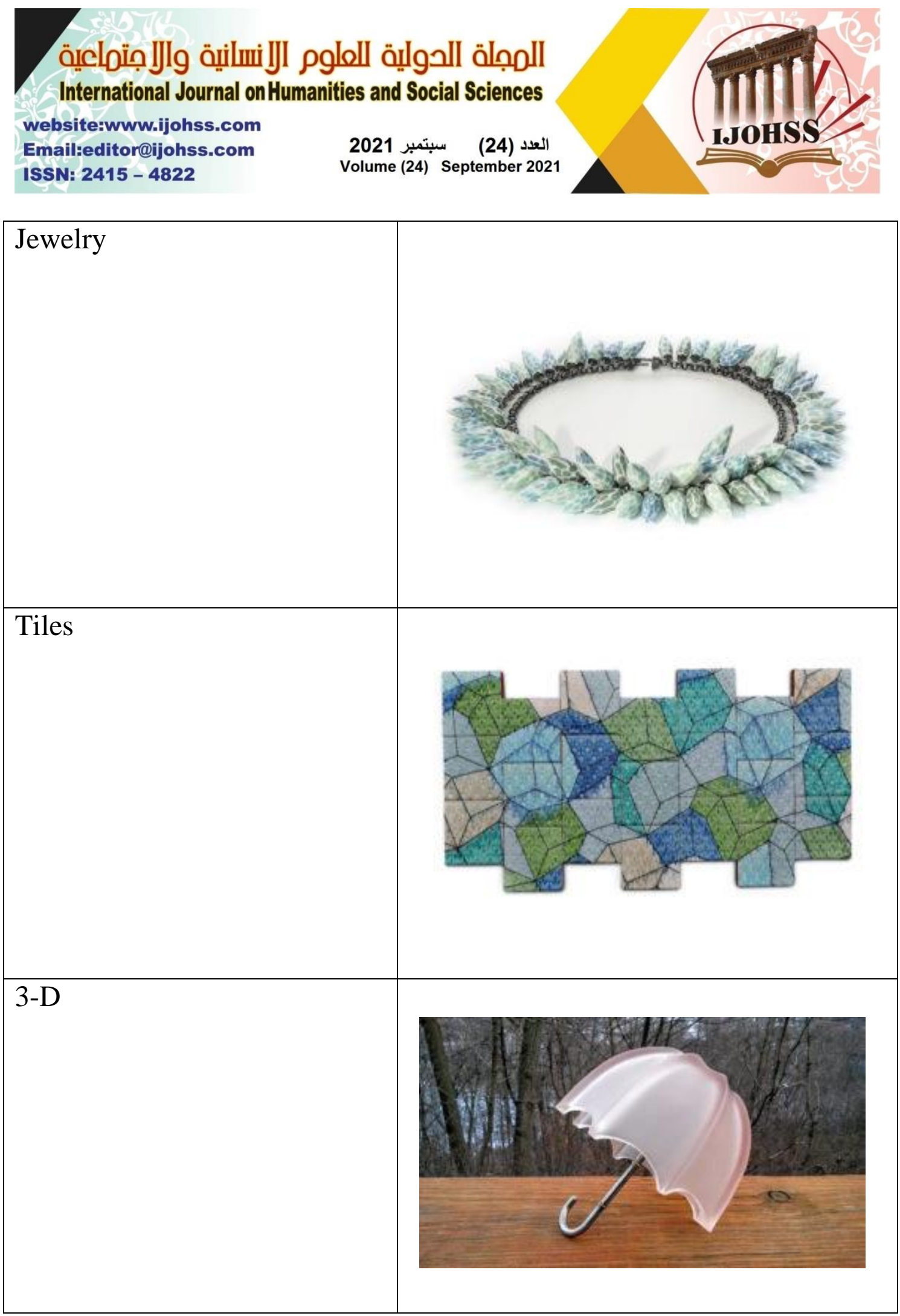
المجلة الحولية اللملوم الإنسانية والإمتماعية International Journal on Humanities and Social Sciences website:www.ijohss.com Email:editor@ijohss.com ISSN: 2415 - 4822
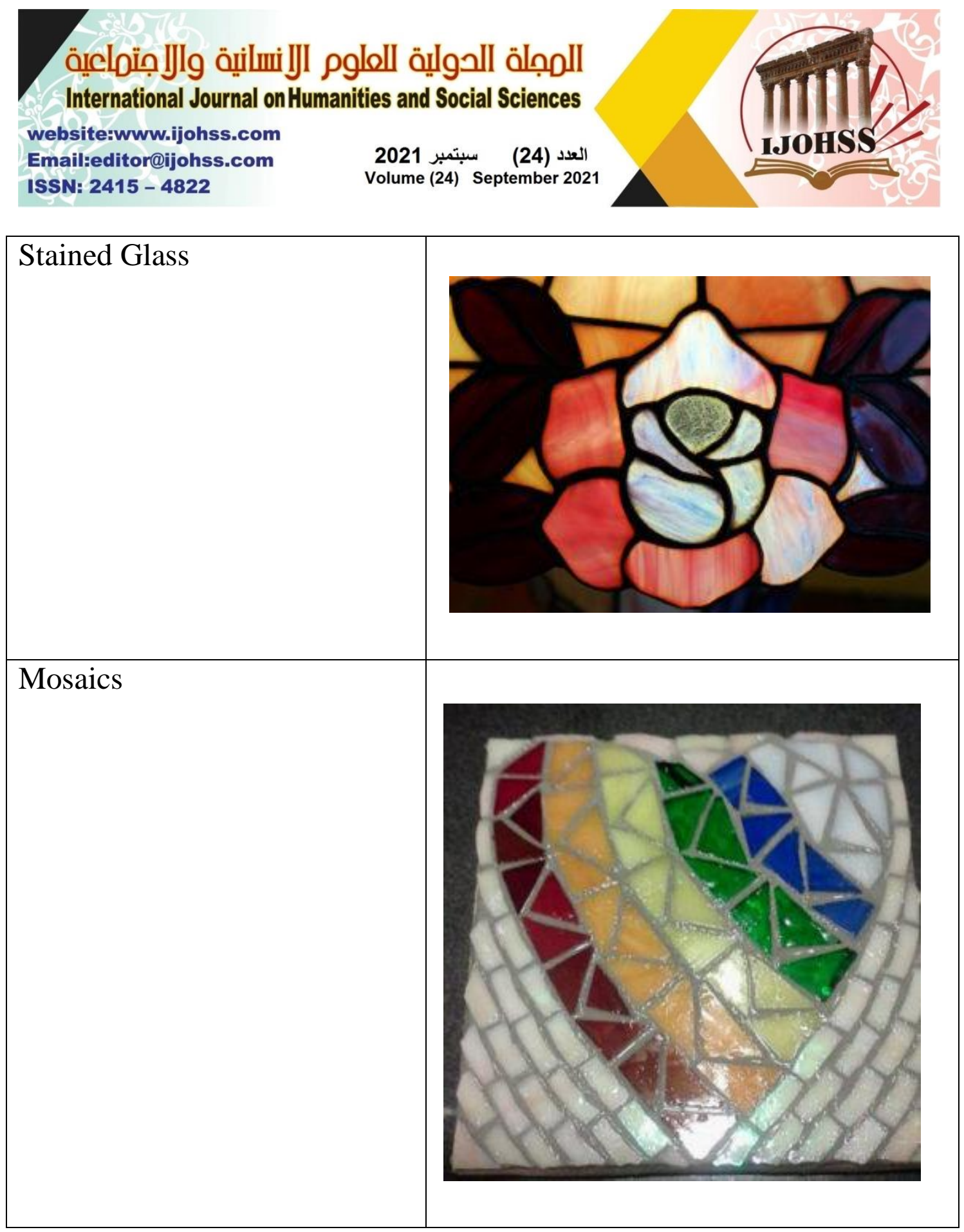
المجلة الحولية اللعلور الأسانية والإمتماعية International Journal on Humanities and Social Sciences website:www.ijohss.com Email:editor@ijohss.com ISSN: 2415 - 4822
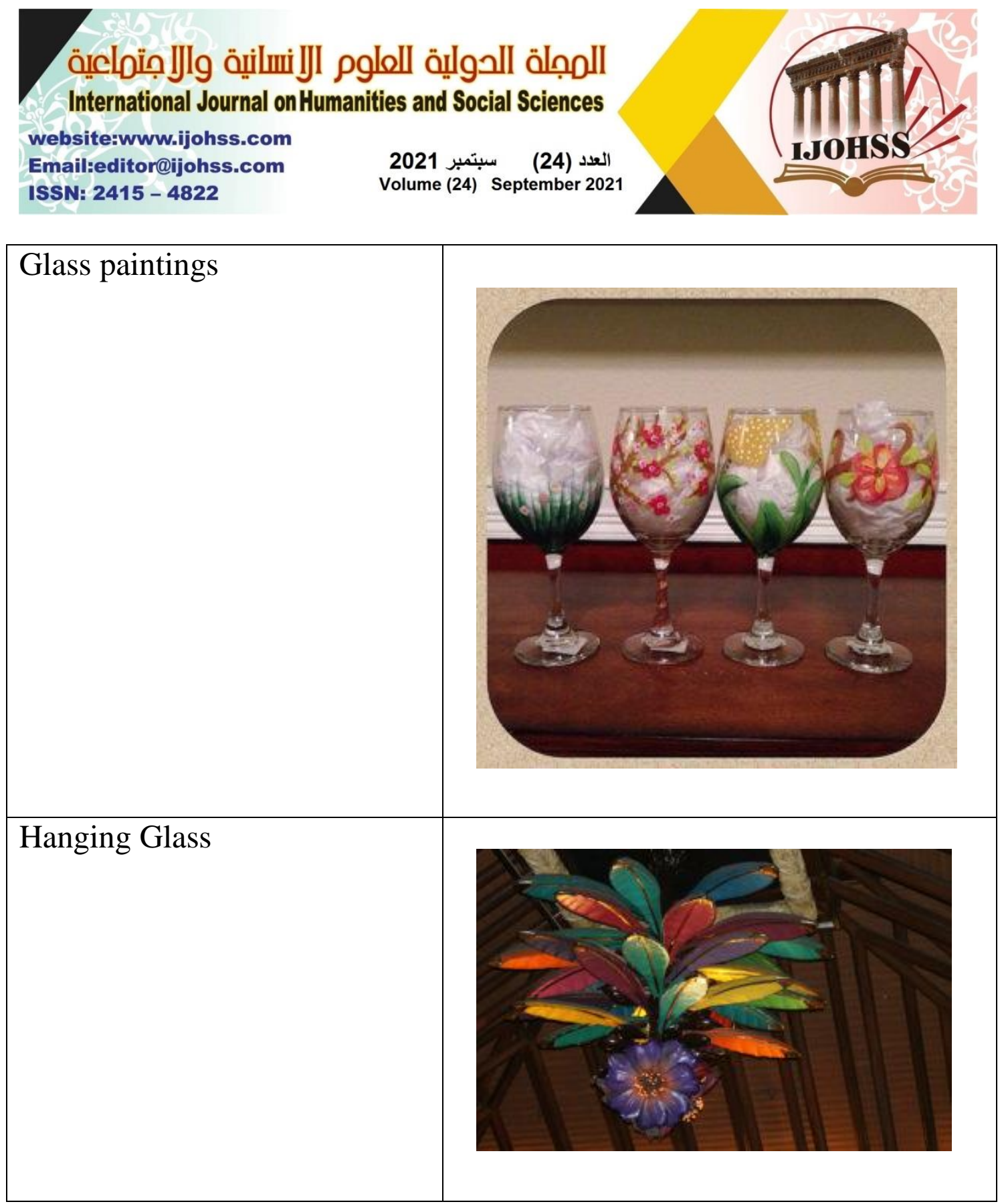

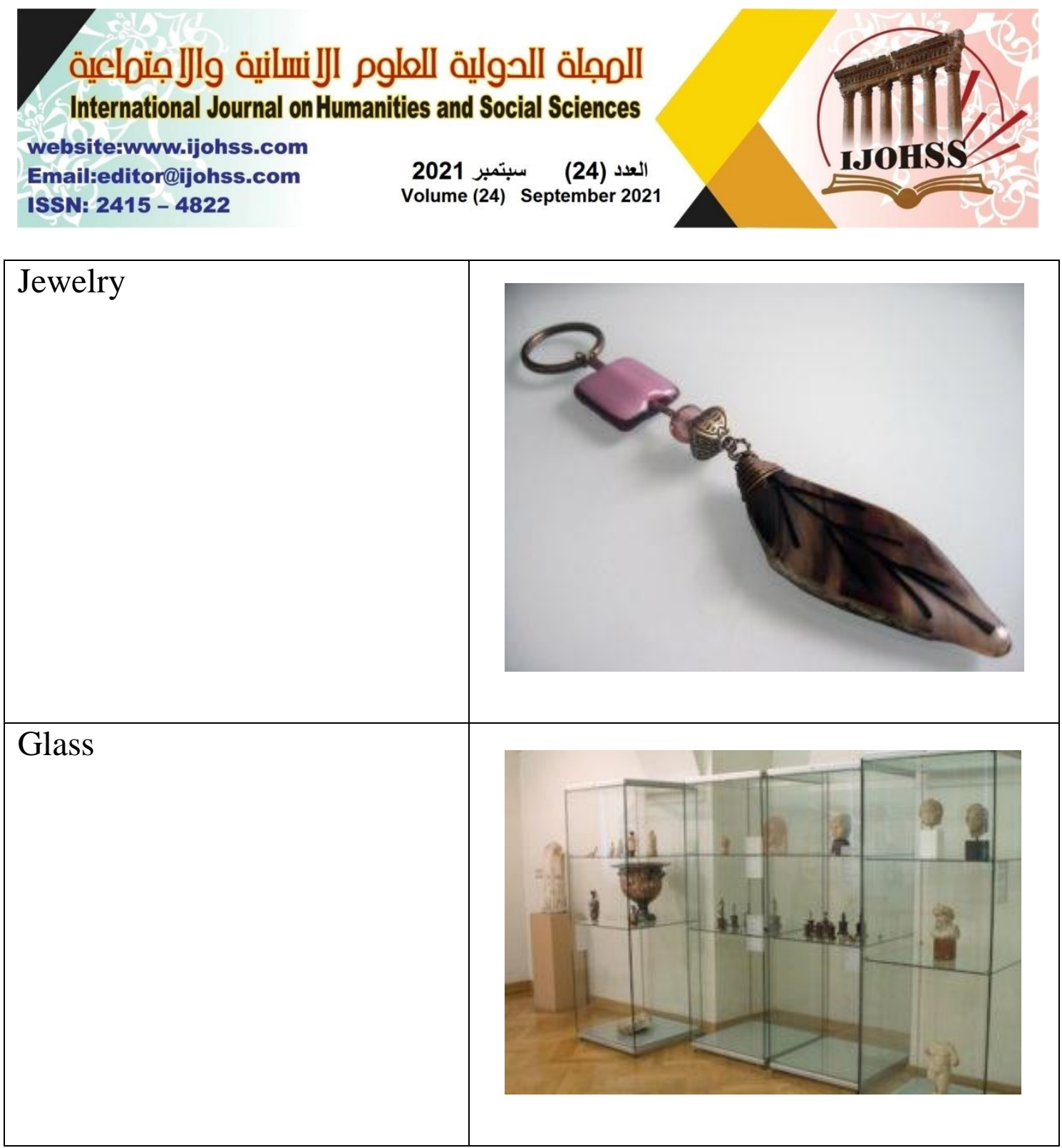

\section{CONCLUSIONS}

Occurrence of modernization, fine art become lesser about artistic and altered their concentration more to denounce towards immense conception of art. In the midst this change, the evolution has arrived, which concentrated the concept and intellective ambition towards autistics. Fine art is one of the arts known. Fine art is known as "a visual art that is contemplate to have been originate in essence for artistic and creative purposes and evaluate for its beauty and full of meanings. This word "fine" does not express the aspect of the artistry in question, but the cleanliness of practice confers to traditional Western European canons. Graphic art spread expansive range of visual aesthetic interpretation, mainly 2-D, for example produced on a flat surface. In 2500 $\mathrm{BC}$, the Egyptians were use graphic arts to symbolize to disseminate their reflection of their thinking's in a written form known as hieroglyphics. Since archaic times, 


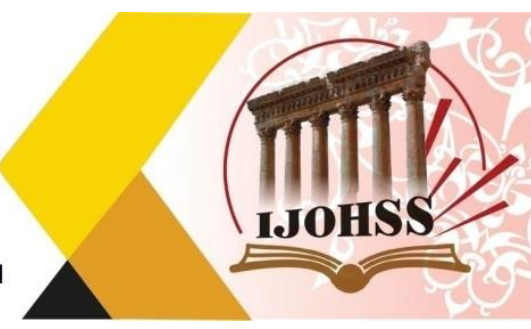

ceramics and glass has been combined with incredible artistry. Ceramics and glasses used widely in fine arts nowadays.

\section{ACKNOWLEDGEMENT}

We would like to express my special thanks of gratitude to the College of Engineering, AL-Muthanna University for supporting this Research.

\section{REFERENCES}

[1] C. Kittel, Introduction to Solid State Physics, Wiley Eastern Limited (5th Edition).

[2] Ceramics materials, 2013, The free encyclopedia.

[3] D.W. Richerson, Modern Ceramic Engineering, 2nd Ed., Marcel Dekker Inc., 1992, ISBN 0-8247-8634-

[4] Green, D.J.; Hannink, R.; Swain, M.V. (1989). Transformation Toughening of Ceramics. Boca Raton: CRC Press. ISBN 0-8493-6594-5.

[5] John B. Wachtman, Jr., ed., Ceramic Innovations in the 20th century, The American Ceramic Society, 1999, ISBN 978-1-57498-093-6.

[6] M.N. Rahaman, Ceramic Processing and Sintering, 2nd Ed., Marcel Dekker Inc., 2003, ISBN 0-8247-0988-8.

[7] M.W. Barsoum, Fundamentals of Ceramics, McGraw-Hill Co., Inc., 1997, ISBN 978-0-07- 005521-6.

[8] Subedi,M.M., An Experimental Study on Electrical Behavior of (Pb1- xSnx ) TiO3 ( $x=0.10,0.20,0.30)$ Ceramics, Dissertation Submitted to the CDP, T.U, Nepal 